\title{
Suplementos antenatales para reducir el riesgo de bajo peso al nacer
}

Effects of alternative maternal micronutrient supplements on low birth weight in rural Nepal: double blind randomised community trial. Parul Ch, Khatry SK, Katz J.BMJ Mar 2003; 326:571-576.

\section{Objetivo}

Evaluar el impacto de la suplementación de distintas combinaciones de micronutrientes a las embarazadas sobre el tamaño al nacer y el riesgo de bajo peso al nacer.

\section{Diseño}

Ensayo aleatorizado controlado doble ciego. La unidad de aleatorización fueron sectores dentro de aldeas.

\section{Lugar}

Comunidad rural en el sur-este de Nepal.

\section{Pacientes}

Se aleatorizaron 426 sectores en 30 aldeas (aleatorización por clusters, utilizando una secuencia en bloques de a cinco). La asignación de la intervención se realizó sacando chips numerados de un sombrero. Las mujeres de un sector podían recibir uno de los siguientes cinco suplementos:ácido fólico $(400 \mu \mathrm{g})$, ácido fóli$\mathrm{co}+$ hierro (60 mg de fumarato ferroso), ácido fólico + hierro + zinc (30 mg de sulfato de zinc), o ácido fólico + hierro + zinc + un complejo multivitamínico ( vitamina D $10 \mu \mathrm{g}$, vitamina E $10 \mathrm{mg}$, vitamina B $11,6 \mathrm{mg}$, vitamina B-2 $1,8 \mathrm{mg}$, niacina $20 \mathrm{mg}$, vitamina B-6 2,2mg, vitamina B-12 2,6 $\mathrm{gg}$, vitamina C $100 \mathrm{mg}$, vitamina $\mathrm{K}$ $65 \mu \mathrm{g}$, cobre $2,0 \mathrm{mg}$, magnesio $100 \mathrm{mg}$ ) todos con vitamina $A$ y vitamina A solamente $(1.000 \mu \mathrm{g})$ como grupo control.

\section{Intervención}

4926 mujeres embarazadas recibieron uno de los 5 suplementos y 3787 recién nacidos vivos fueron evaluados en su antropometría. Los suplementos (botellas y cápsulas) fueron idénticos en apariencia y los participantes, investigadores, el personal de campo y estadísticos fueron ciegos a la intervención.

\section{Principales medidas de resultado}

Resultado primario: Peso del recién nacido evaluado dentro de las 72 horas del nacimiento.

Otros resultados: talla, circunferencia cefálica y torácica, bajo peso al nacer BPN $(<2500 \mathrm{~g})$, pequeño para la edad gestacional y pretérmino. Los datos fueron analizados según intención de tratamiento.

\section{Resultados}

Comparados con el grupo control, ni la suplementación materna con ácido fólico ni la suplementación con ácido fólico+hierro+zinc, tuvieron efecto sobre el tamaño al nacer. En cambio, la suplementación con ácido fólico+hierro aumentó la media de peso al nacer en $37 \mathrm{~g}$ (IC 95\%: -16 g a $90 \mathrm{~g}$ ) y redujo el porcentaje de niños con bajo peso al nacer $(<2500 \mathrm{~g})$ en un $16 \%$ RR=0.84 (IC95\% $0,72-0,99)$. La suplementación con múltiples micronutrientes aumentó el peso al nacer en $64 \mathrm{~g}(12 \mathrm{~g}$ a $115 \mathrm{~g})$ y redujo el porcentaje de niños con bajo peso al nacer en un $14 \% \mathrm{RR}=0,86$ (IC95\% 0.74 - 0,99). Ninguna de las combinaciones redujo la incidencia de nacimientos pretérmino.Tanto la suplementación con ácido fólico+hierro como la de múltiples micronutrientes incrementaron la circunferencia cefálica y torácica, pero no la talla.

\section{Conclusiones de los autores}

La suplementación antenatal de ácido fólico+hierro reduce el riesgo de bajo peso al nacer. La suplementación con múltiples micronutrientes no confiere ningún beneficio adicional sobre el ácido fólico+hierro para reducir este riesgo.

\section{Comentario}

La calidad metodológica del estudio es adecuada (aleatorizado, controlado, doble ciego).Sin embargo, es de destacar que el $20 \%$ de los recién nacidos no fue analizado (pérdidas y exclusiones) lo cual puede modificar los resultados y debilitar sus conclusiones. En cuanto a los resultados tanto el grupo que recibió ácido fólico + hierro, como el grupo que recibió múltiples micronutrientes, mostraron una reducción estadísticamente significativa en el riesgo de BPN (RRR ajustada de $16 \%$ y $14 \%$ respectivamente). El NNT reportado en el estudio estima que se deberían tratar a 11 mujeres con ácido fólico-hierro o 12 con micronutrientes para evitar el nacimiento de un niño con bajo peso. En cuanto al peso al nacer, los recién nacidos cuyas madres recibieron ácido fólico + hierro si bien pesaron en promedio $37 \mathrm{~g}$ más que el grupo control, esta diferencia no fue significativa (-16 a 90).Los RN cuyas madres recibieron micronutrientes pesaron 64 gramos más que los del grupo control (IC 95\% 12 a 115) De los resultados se desprende entonces que los micronutrientes aumentan el peso al nacer y reducen el BPN.El ácido fólico+hierro en cambio redujo BPN pero no podemos afirmar que logre aumentar la media de peso al nacer.
La evidencia que surge de este estudio favorece al grupo micronutrientes a pesar de que los autores concluyan que no tienen ventajas sobre el ácido fólico+hierro.

¿Cuáles son los eventuales beneficios en la salud y la sobrevida de un recién nacido por pesar 37 o 64 gr más? Recordemos que no siempre el hecho de que un recién nacido pese más mejora su salud o sobrevida como refieren los propios autores.Sin embargo la evaluación de sobrevida de estos $\mathrm{RN}$ a los 6 meses no fue publicada. Hubiera sido importante contar con la medida de muerte fetal, ya que el hierro podría tener algún efecto en este resultado ${ }^{\text {, así co- }}$ mo otros resultados de morbilidad y mortalidad neonatal.

Conclusión del comentador: Los resultados de este estudio pueden ser aplicables en nuestra Región, en aquellas comunidades con características similares a las mujeres de Nepal, que pesaban en promedio $43,5 \mathrm{~kg}$ debido a malnutrición energética y proteica. En Latinoamérica, probablemente las implicancias de este estudio sean menos importantes ya que la indicación de micronutrientes en mujeres con malnutrición es el estándar de cuidado, no tanto por su efecto perinatal, sino por su efecto sobre el estado nutricional materno. 